\title{
Socio-scientific inquiry-based learning: An approach for engaging with the 2030 Sustainable Development Goals through school science
}

\author{
Ruth Amos* and Ralph Levinson - UCL Institute of Education, UK
}

\begin{abstract}
Socio-scientific inquiry-based learning (SSIBL) incorporates the European Commission's approach to Responsible Research and Innovation (RRI). These relationships are elaborated into a pedagogic model encouraging young people to ask real-world questions that interest them, collect evidence to answer the questions and, as a result, to take personal action on their findings. After depicting a pedagogic model for SSIBL, we identify the opportunities for pre-service science teachers (PSTs) adopting a SSIBL approach. We detail SSIBL activity designs that aim to engage students in learning about the 2030 Sustainable Development Goals. The findings show the prerequisite of using the science curriculum to facilitate SSIBL within the Sustainable Development Goals (SDGs). We suggest a SSIBL approach would benefit from co-designed frameworks involving the collaboration of cross-disciplinary groups of teachers, through reflection and enactment on previous SSIBL activities. SSIBL enables practitioners to establish engaging contexts for science knowledge development, as well as to become more informed citizens.
\end{abstract}

Keywords: inquiry learning; pedagogy; science; society; activism

\section{Introduction}

One of the main challenges for contemporary science and technology in Europe is informing democratic citizenship of the benefits, risks and ethical applications of developments. The uncertainties and hazards associated with technologies such as nanotechnology, genomics and robotics have been characterized as post-normal science (Funtowicz and Ravetz, 1993, 1994; Ravetz and Funtowicz, 1999). They exemplify the corporatization of science - the potential for vast profits from the huge changes generated by these technologies, together with hazards, risks and uncertainties. In launching the 2030 Sustainable Development Goals (SDGs; UN, 2015), following on from the Millennium Development Goals, heads of state and government reaffirmed the urgent need to tackle a wide range of issues at individual, local and global levels, in which science and technology play an integral part. Challenging poverty, environmental degradation and poor health, for example, must be at the forefront of these commitments and, if younger generations are to become responsible citizens, education has an important role to play (Bourn et al., 2017).

Responsible Research and Innovation (RRI) is a European initiative (Sutcliffe, 2011) designed to address this continuing concern and to align scientific research both with and for society (Owen et al., 2012), where products of research in science and technology have to meet standards of sustainability, social desirability and ethical 
acceptability (Von Schomberg, 2014). There is therefore potential for RRI strategies, among other important pedagogical frameworks (for example, Yates, 2018), to guide teachers in providing students with opportunities to engage with working towards, and understanding, sustainability (Bourn, 2016) and the SDGs. During the period 2014-17, a European project entitled Promoting Attainment in Responsible Research and Innovation (PARRISE; www.parrise.eu), run by a consortium of 18 higher and informal education institutions from 11 countries, took place. In developing the project, we took RRI as our overarching pedagogic context for an inquiry-based approach: socioscientific inquiry-based learning (SSIBL). The project aimed to build pre-service (PSTs) and experienced primary and secondary science teachers' confidence, skills and knowledge for teaching through SSIBL. This article outlines some of the outcomes of the project, as science PSTs were trained and supported in designing SSIBL activities for lower secondary school students in London, UK, as part of their one-year initial teacher education programme, the Postgraduate Certificate in Education (PGCE). We present relevant opportunities that PSTs found while identifying areas of the curriculum related to the SDGs, and also discuss the challenges they faced in adopting the SSIBL approach as early career teachers. One of the goals of the PARRISE project was to prepare science PSTs to contribute to teaching through an 'it matters' approach in the context of the English national curriculum's (DfE, 2015) intended scientific ideas and inquiry skills. This therefore aligns well with citizenship attributes desirable for contributing to the SDGs.

\section{Socio-scientific inquiry-based learning (SSIBL)}

SSIBL brings together three supporting and mutually interactive pillars, namely, learning through socio-scientific issues (SSI), incorporating citizenship education, and inquiry-based science education (IBSE). The PARRISE project developed three main stages to the SSIBL approach (Levinson et al., 2017):

- raising an authentic research-based question about a socio-scientific issue

- research-based inquiry on the question to enact change (for example, carrying out experiments and/or surveys, analysing data, collaborating with others)

- finding a solution (for example, communicating results based on evidence from research, convincing others of the necessity for change, particularly those who have influence to carry out change, taking personal action).

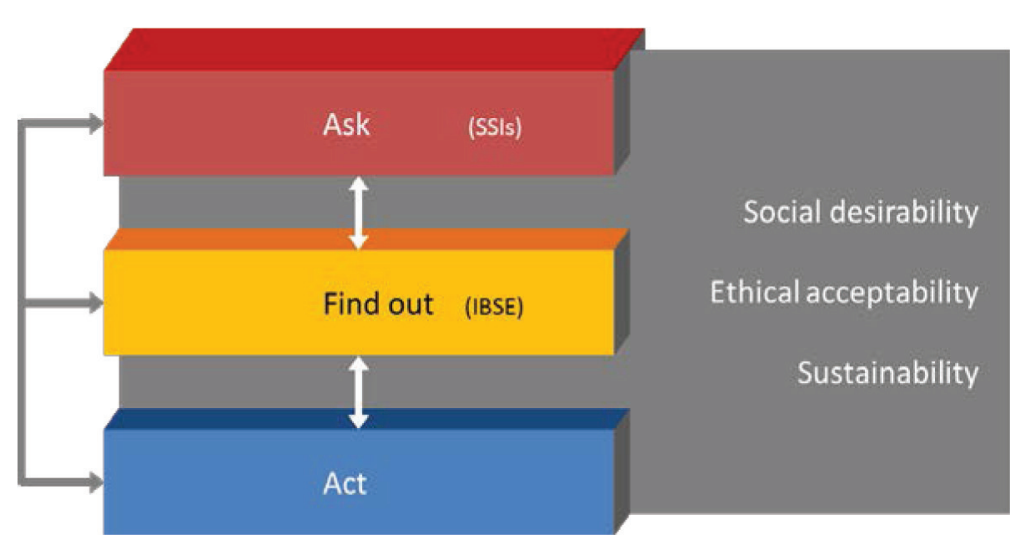

Figure 1: The SSIBL approach sequence 
Although this might be the expected sequence, it is perfectly possible to have a proposed solution to a problem then, through an inquiry-based approach, to collect the necessary evidence to underpin the solution. The sequence can be summarized as Ask-Find Out-Act (see Figure 1).

The more detailed SSIBL approach is represented in Figure 2.

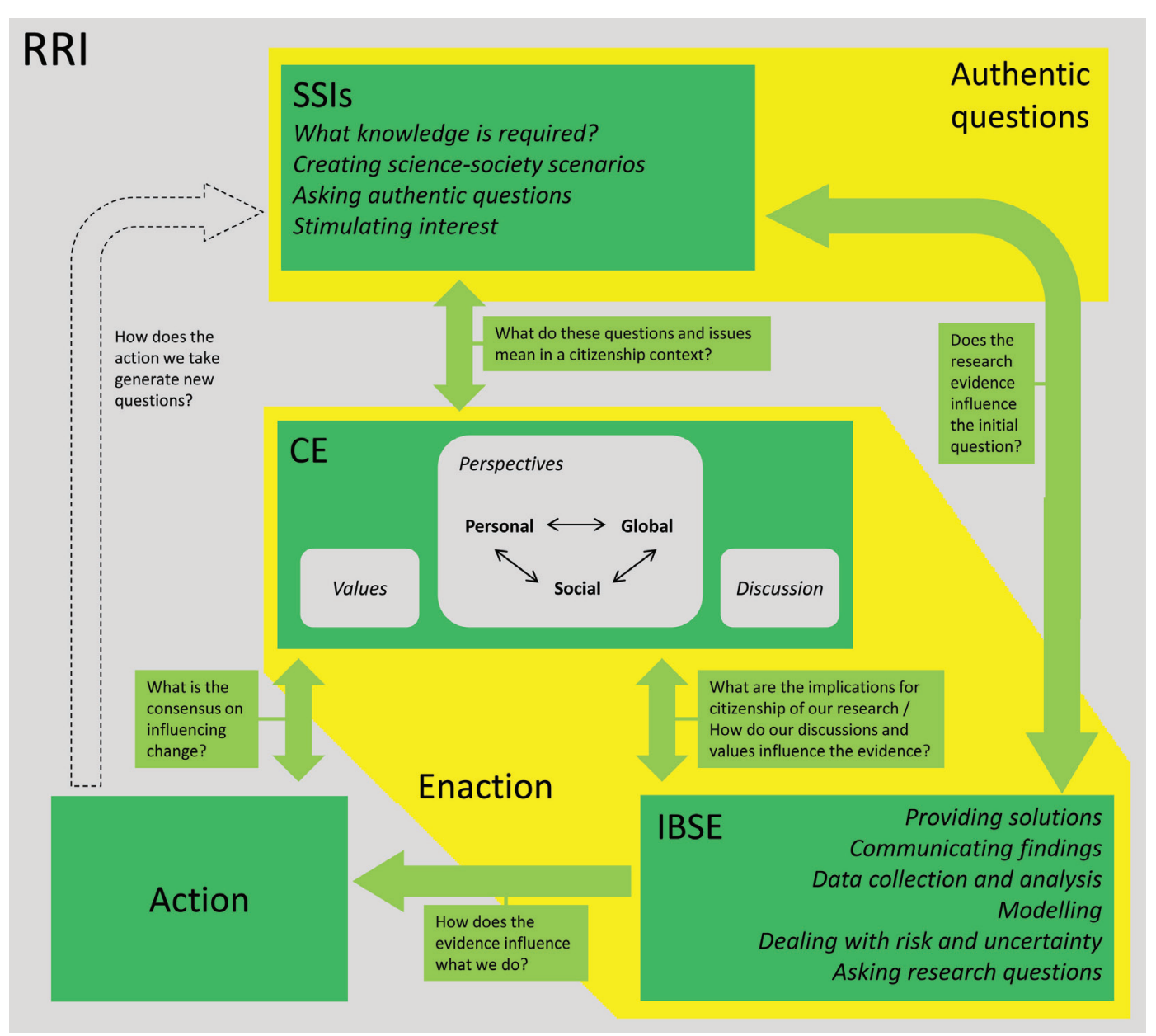

Figure 2: The detailed SSIBL approach

SSIs can incorporate authentic research questions arising from student interest, relevant socio-scientific scenarios and the pedagogic strategies to support student interest and commitment (Sadler, 2009). In relation to the 2030 SDGs, there are important societal questions arising from scientific and technological innovations, which can act as overarching themes for SSIBL. On a global level, these include issues concerning health and disease, climate change and environmental degradation. European science curricula typically incorporate requirements for school students to become capable decision-makers using science inquiryskills (Amos etal., in press). IBSE involves collecting the necessary evidence to address a research question, modelling potential solutions, examining attendant risks and uncertainties and generating potential solutions. The data, evidence and solution have to be iteratively fed back to the research question to check whether the evidence is consistent with the question. Sometimes this might lead to adjusting the research question. School students naturally need support in refining inquiry questions, and in the PARRISE project, PSTs practised the necessary scaffolding by developing and refining their own questions. Citizenship education 
relates to sociopolitical questions, which then enact change based on just solutions to a problem, explicating values that incorporate an understanding of social desirability, ethical acceptability and sustainability, engaging in deliberative dialogue (Levinson, 2010) and understanding the connections between individual, social and global issues (see the example of Catalytic Clothing below). To operationalize the SSIBL approach for school science teachers, the three stages are elaborated as follows.

\section{The SSIBL approach}

\section{Raising authentic questions - Ask}

In SSIBL, our conceptualization of authenticity is based on problems arising from the 'interests, perspectives, desires, and needs of the students' (Buxton, 2006: 701). Brickhouse (2011) prefers non-formal approaches through out-of-school environments, although inquiries can be used to identify school-based questions, such as sustainable and improved school heating systems, e-cigarettes for young people trying to stop smoking or monitoring and reducing pollution around the school. Bringing in experts, or initiating thinking about SSIs via real-world experiences, can be fruitful (Zangori et al., 2017), although in the UK context this seems to be a continuing challenge, and so simulated socio-scientific problems can be of some value (Simon and Amos, 2011). Roth (1997) focuses on the sociocultural nature of inquiry, practices shared within a community of inquiry, common goals and purposes negotiated, and knowledge recontextualized.

In a study on teaching authentic science inquiry, Buxton (2006) identified the following prerequisites: willingness of teachers to adopt a model of curriculum that links to issues of personal and local interest, and taking advantage of 'teachable moments'. Working towards the 2030 SDGs therefore means science teachers keeping abreast of current issues in the fields of, for example, health, environment and ecosystems, energy and material resources (UN, 2015), which link with the taught national curriculum. This in itself is a challenge for busy teachers. As noted earlier, in raising inquiry questions, students are likely to respond to authoritative direction in the form of teacher scaffolding (Davis and Miyake, 2004). Pre-service science teachers are therefore in an ideal position to practise such scaffolding as part of their initial training, in learning to design and structure activities with varying degrees of support for students, including asking 'trigger' questions and using stimuli such as photographs, video extracts, newspaper cuttings and Twitter feeds.

\section{An inquiry-based approach - Find out}

Adopting an inquiry-based approach to address authentic socio-scientific questions derives from creativity, as well as possibilities for inquiry in EU policy for science education (Rocard et al., 2007), and has a recent history of evidenced advocacy (Brickman et al., 2009; Wilson et al., 2010). What is meant by inquiry-based approaches, however, has a range of interpretations. Abd-El-Khalick et al. (2004) distinguish between inquiry as a means to help students understand science content and inquiry about science involving learning about epistemic aspects of science practice and development of knowledge. In the context of our study, the emphasis is on 'inquiry about science', although such an approach does not preclude gaining knowledge of science ideas.

In our study, inquiry has a broader interdisciplinary aspect to indicate the processes of finding answers to open socio-scientific questions involving research, data 
collection and reflection. The focus of research and data collection in SSIBL comprises collection of data through social research, such as surveys and interviews, as well as scientific experiments. While this interpretation is loose, it allows us to refine any depictions of inquiry through accumulating experience and theorization of research. By engaging in this authentic research activity, where local and global issues related to scientific and technological development have been identified as having societal impacts, students can explore key aims within several of the SDGs.

\section{Finding a solution - Act}

Finding a solution presupposes change, if the inquiry is to retain authenticity. For instance, Krstovic (2014) reports an approach known as research-informed action (RiA). This has enabled high-school students to raise awareness about how powerful corporations operate. They use evidence-based research to produce, for example, videos, brochures and posters, devising new impact-information labels for consumers of plastic water bottles, and class presentations to lobby for action. Krstovic (2014) discusses the necessity for scaffolding such studies by directing collaborative groups to identify correlations with possible reasons, and providing further evidence through secondary research. In preparing for RiAs, Krstovic suggests that students are encouraged to clarify the issue, identify what they already know and what they would need to learn, propose an idea for a survey, and decide on reasons to take action on the issue. This has parallels with our PARRISE project. In this article, we highlight some of the opportunities established, and challenges faced, by PSTs, in planning for students' taking action as a result of inquiry findings about issues concerned with the SDGs during SSIBL.

As part of their training programme, we present PSTs with scenarios and models for introducing SSIBL, stimulated by contemporary local and global issues. One such scenario is the story of Catalytic Clothing.

\section{Catalytic Clothing: Living sustainably in action?}

To exemplify the tensions within sustainability programmes in EU countries, and the pertinence for a SSIBL approach, the development of Catalytic Clothing offers insights into the complexity of becoming a critical citizen. Catalytic Clothing came about as a result of a collaborative idea by a fashion designer (Helen Storey) and a research chemist (Tony Ryan), which sought to provide a solution to city air pollution from motor vehicle emissions (see Etherington, 2011). Tony's work with polymers led him to explore the viability of using clothing as a consumer-friendly way of reducing air pollution. Items of clothing are designed in such a way that they can be impregnated with a photocatalyst (titanium dioxide) that adheres to the fabric. This can be done by washing them using a specific detergent. When the clothes are exposed to the atmosphere, the catalyst, activated by sunlight, removes pollutant nitrogen oxide (NOx) products (mainly produced by cars and buses) from the air and breaks them down through a series of chemical reactions. The nitric acid and nitrates produced can be washed off clothes easily, and they are less hazardous than NOx.

While attempting to put this exciting project into action by persuading laundry product manufacturers to take on the idea, challenges with technical and cost-related issues persisted. These included the extent to which the wearing of such clothes could make a significant difference: in other words, how many people would have to wear them, and for how long, to make any significant reduction in atmospheric pollutants? Other technical problems are those common to clean-up technologies where the 
solution can pose risks as great as the original problem. Although soluble nitrates are less immediately harmful than NOx emissions, the drained nitrates can promote eutrophication in waterways such as canals and rivers, as well as blood disorders and thyroid problems if they enter the water supply. Furthermore, the behaviour of titanium dioxide nanoparticles is unpredictable (Burton, 2012).

Despite some of the potential drawbacks, Catalytic Clothing exemplifies an unusual aspect of sustainability as a result of collaboration between art and science. If it were possible to carry out risk analyses in weighing up the relative hazards of nitrate run-off against the benefits of helping to reduce NOx emissions, it would address some aspects of sustainability (in SDG 12.4), as well as social desirability in having overall benefit for the community, at least at a local level. From an environmentalist perspective, a disadvantage is that clean-up technologies are not a means of reducing the production of pollutants, which should not be in the air in the first place. This is a considerable issue, and therefore we include the Catalytic Clothing example in the training of PSTs to illustrate the depth of awareness and knowledge that science teachers need in order to support their students in understanding complexities within SSls (Levinson et al., 2017).

A deeper problem stems from the question of ethical acceptability. At a local level, the ethical issues seem minor. The use of such clothing would demonstrate wearers' willingness to address the problems of atmospheric pollution. However, this is where a global perspective focusing on production is crucial in demonstrating the close links, politically and ontologically, between the local, social and global. None of the literature about Catalytic Clothing mentions the production of titanium dioxide. Shifting the perspective towards production reveals what is not immediately apparent. Titanium dioxide is extracted from the mineral ore, rutile. The largest rutile mines are in Sierra Leone, West Africa, one of the world's poorest countries. According to figures published by the World Health Organization in 2008, 'one child out of seven [dies] before reaching the age of five' (SSL and ICF Macro, 2009: 7), and in 2018 it was ranked 184 out of 189 countries in the UN Human Development Index (UNDP, 2018: 25). Until about 2016, the country was also devastated by the Ebola virus.

While the mining industry forms about 90 per cent of Sierra Leone's economy, the country's inhabitants have benefited very little from rutile mining because of environmental damage, displacement and impoverishment of populations around the mines without appropriate compensation, loose regulations and global corporates benefiting from lax tax laws (NACE, 2009). A bribery scandal in 2016 suggests that little has improved over the last ten years (see lannucci, 2017). The issues involved highlight the key aspects of the SSIBL process (see Figure 2).

The Catalytic Clothing example illustrates one of the biggest challenges facing teachers who wish to teach through the SSIBL framework: gaining access to up-todate, well-balanced knowledge and information about the complexity of issues within a problem. There are many instances such as this, which seem on the surface to offer purposeful actions for sustainable living, but when explored more deeply reveal unanticipated, undesirable consequences. Raising school students' awareness of the contradictions inherent in using and consuming products, particularly where divisions and issues arise between developed and developing countries, is a vital goal for science education at all levels (Gray et al., 2009). An advantage of the SSIBL approach is that it encourages asking questions and collecting evidence at individual, local and global levels. In clarifying questions of ethical acceptability, it can raise new questions about what is socially desirable and what is presupposed in evaluating a product as 'sustainable'. This exposes problematic links between production and 
consumption. There are other examples that lend themselves through inquiry to exposing these deeper questions, for example, the production and consumption of aluminium (Levinson, 2009, 2014) and the mining of coltan, the raw material used in creating microchips for mobile phones (Lalji, 2007). Again, we used some of these examples with the PSTs as we supported their development of design skills for taking an 'it matters' approach to teaching and learning in school science. The purposes here were:

- to encourage PSTs to reflect on the use of stimulus materials to promote asking authentic questions, and how they might use or adapt such materials through their teaching

- to identify areas of the curriculum in which they could co-design SSIBL activities to enact in their teaching practice (Kyza and Nicolaidou, 2017)

- to plan action-related outcomes with and for students.

In order to explore the experiences of PSTs, we asked the following research questions:

- What are the opportunities for, and challenges faced by, PSTs planning and teaching through SSIBL with secondary school science students?

- How does the SSIBL approach engage teachers and students with the 2030 SDGs?

\section{Methods}

During our PARRISE project (2014-17), 350 science PSTs were trained in the SSIBL approach at UCL Institute of Education, London, UK. This represents four cohorts (numbered 1 to 4 ) in their initial year of training. Our research into PSTs' SSIBL practices formed part of our support as programme tutors for their day-to-day training on the PGCE science programme, in the context of learning to teach. The PSTs gained permission to design and teach SSIBL activities within their schools, and analysed outcomes by evaluative reflection as part of the project. All PSTs' names are pseudonymized.

Where possible in their first placement schools, the PSTs designed SSIBL activities for 11-15-year-old secondary science students by collaborating with experienced mentor science teachers. Activities were situated within the framework of the English national curriculum for science (DfE, 2015), such that while studying specific scientific ideas and skills, PSTs looked for real-world events and stimuli that sparked students' questions about societal and environmental consequences and impacts. They also examined local situations in their schools, where issues concerned with sustainable practices were apparent. This work was also taking place in our 18 partner institutions across Europe during the project, and so applications of SSIBL have been made in different curriculum contexts (see Amos et al., 2018).

We asked the PSTs to document lesson designs and teaching resources and to write reflective accounts of their design intentions and experiences. Approaches that allow for cycles of design-enactment/implementation-reflection not only enable short-term outcomes. According to Kyza and Nicolaidou (2017), they also encourage teachers to promote further changes and possibilities in developing reform within the context of their own practice, such as integrating and disseminating SSIBL in their own departments and schools. This is important when trainees become the next generation of teachers with opportunities to influence and potentially change practice. We adapted Clarke and Hollingsworth's (2002) empirically based non-linear model connecting four domains of teacher change through reflection and enactment (implementation). The model (see Figure 3) is adapted to illuminate practice through SSIBL. 

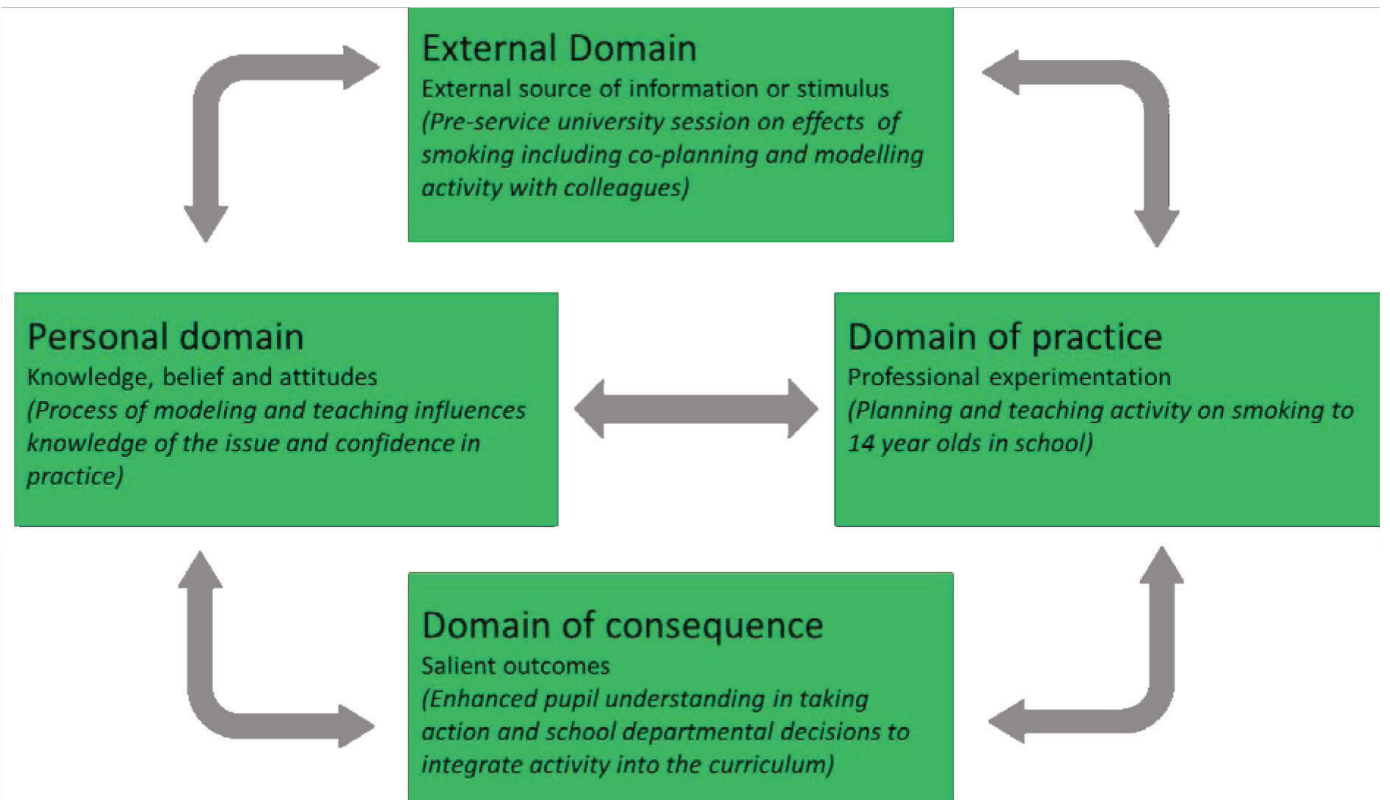

Figure 3: Interconnected model of teacher development (each double-headed arrow reflects the possibility of enactment and reflection)

Source: Adapted from Clarke and Hollingsworth (2002: 951)

The external domain is a means of providing new information or new resources for the teacher, such as pre-service sessions as described above, a lesson a PST has seen that inspires new ideas, an article they have read in a professional journal and talks by scientists. In some cases, the external domain can include all of these. When new initiatives such as the SDGs are unveiled, the external domain can focus on them. It is a means for teachers to become immersed in challenging, contemporary issues linked to the science curriculum, plan in advance and anticipate questions that might engage, and be asked by, students. These activities scaffold practice - the support that helps teachers implement SSIBL in the classroom. Planning, co-designing and teaching through applying learning constitute the domain of practice; for example, Jyran (one of the PSTs discussed below) teaches about the importance of understanding the use and misuse of plastics after training on SSIBL in the university sessions. The personal domain is the effect of change and new practice on teachers' knowledge, beliefs and attitudes. These action-reflection cycles are important if early career (and indeed experienced) teachers are to adapt their practice responsively to bring in contemporary local and global issues such as those highlighted by the SDGs.

In this article, we report on SSIBL activities designed by PSTs that enable school students to engage with the SDGs. We analyse PSTs' documentary evidence using thematic coding derived from the SSIBL approach. These include, for example, types of question stimuli, use of teacher- or student-initiated inquiry questions, research strategies to explore inquiry questions and planned or emerging outcomes. We specifically look for student outcomes in three categories: raising awareness (RA); intention to act (IA); and taking action (TA). By examining these, we hope to establish the success with which PSTs could engage their students in asking, or engaging with, personally meaningful questions, using relevant research approaches and establishing actions in response to their inquiry findings. 


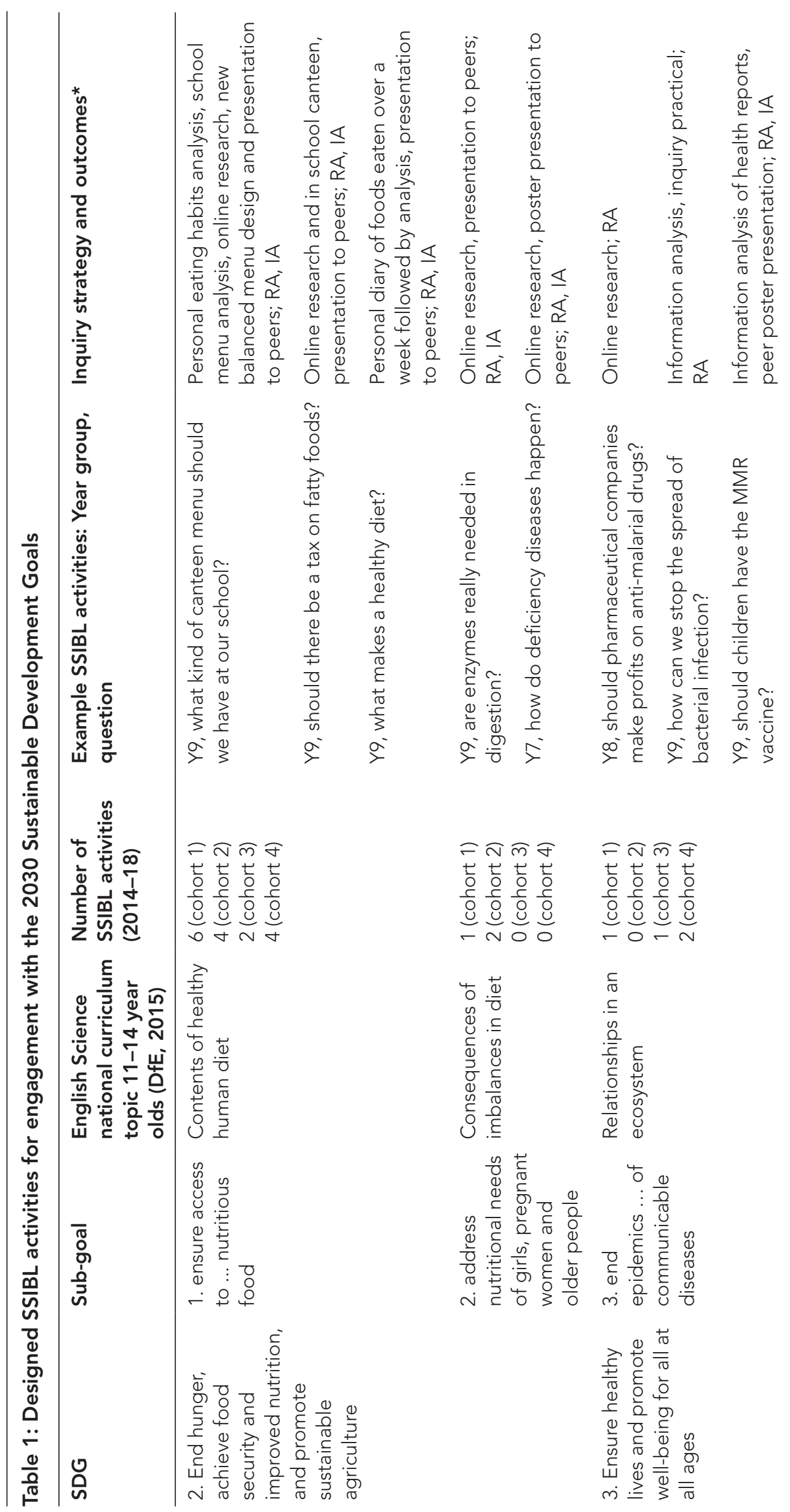




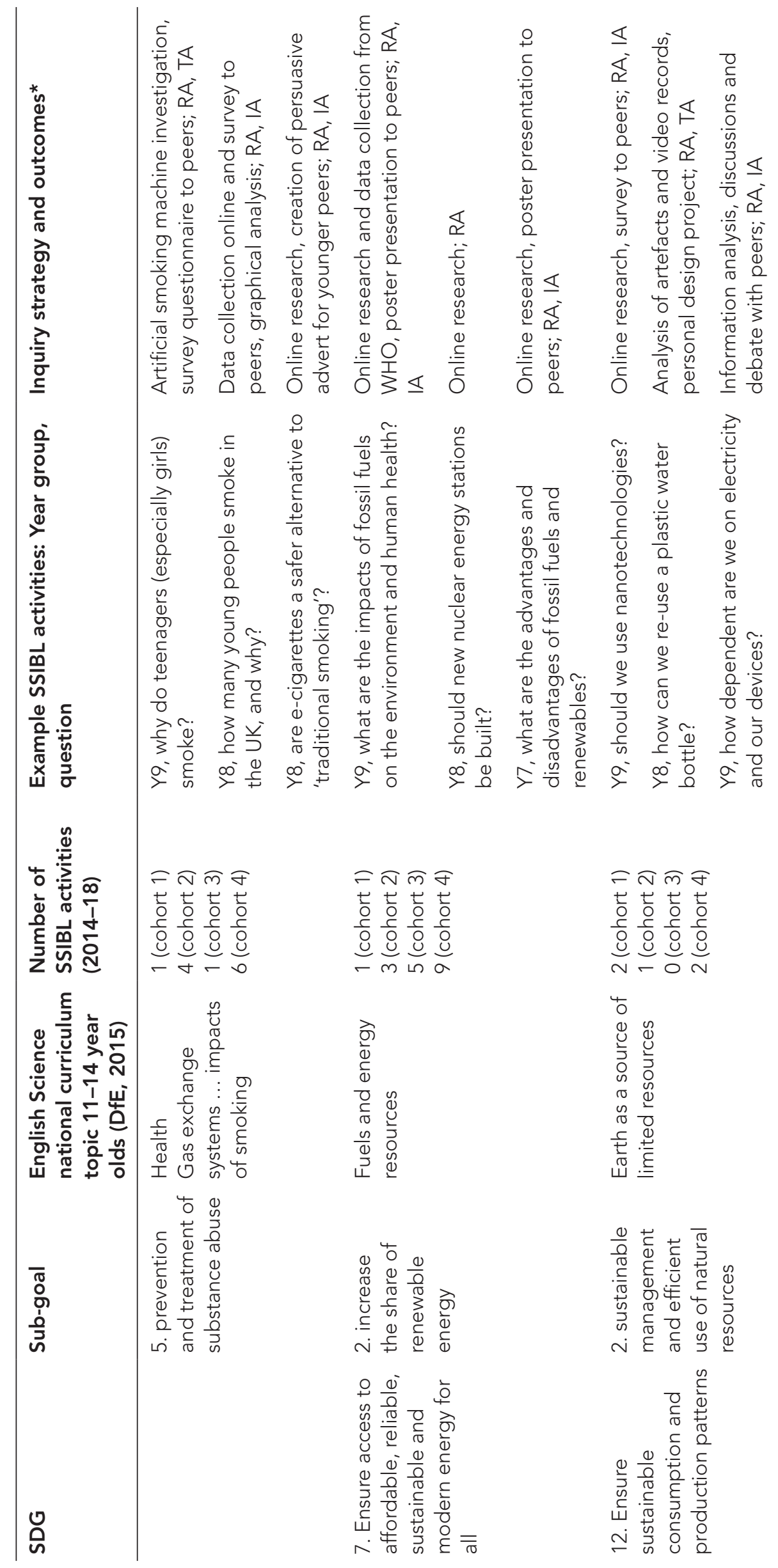




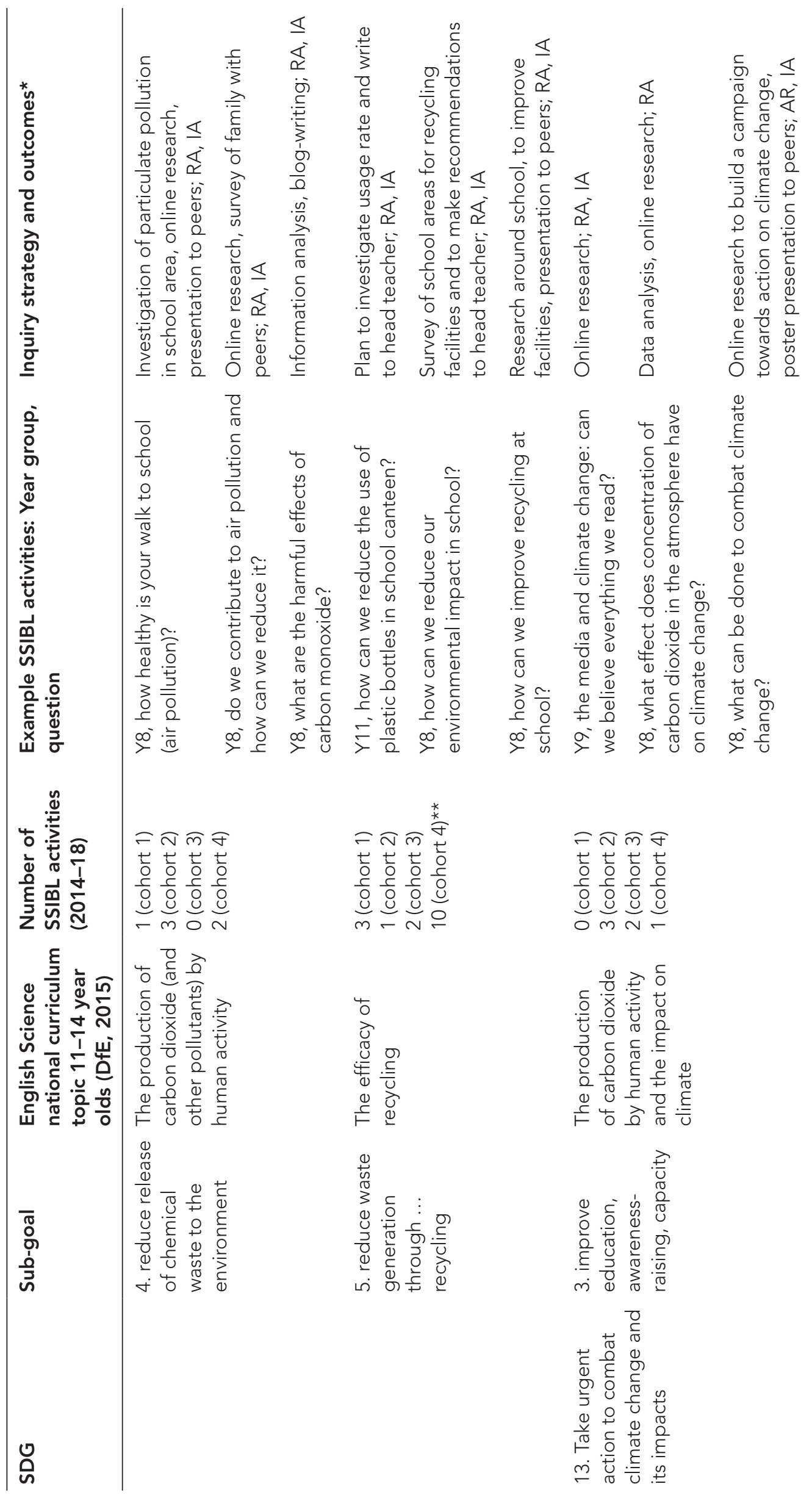




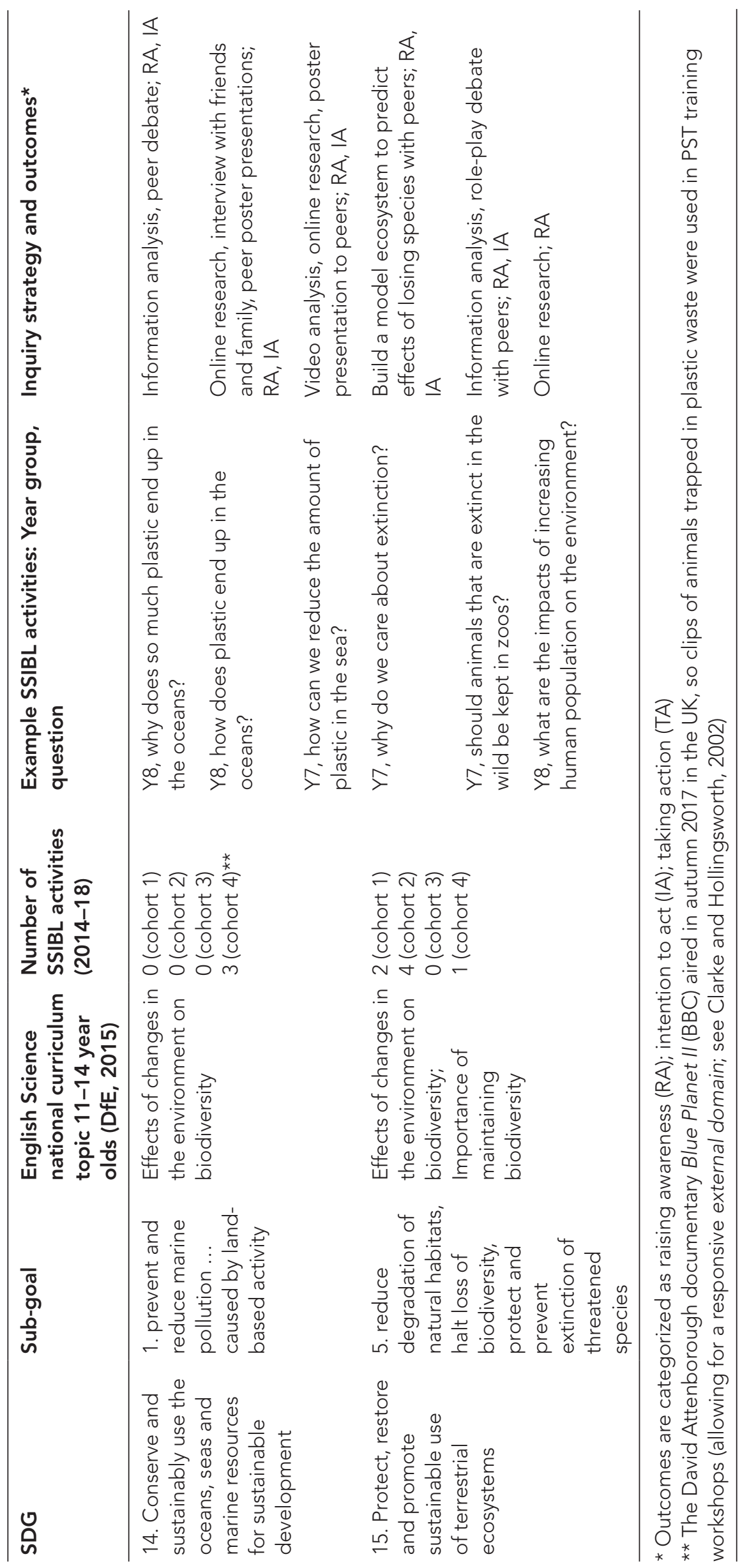




\section{Findings}

PSTs found a wide variety of curriculum opportunities for SSIBL within the English science national curriculum (DfE, 2015). There were tensions between affording the time for high-quality SSIBL activities, even with younger secondary school students (11-14 year olds), and perceived pressures attributed to a content-heavy science curriculum, aimed at preparing students for high-stakes assessment by the end of their secondary school education. However, we were able to establish evidence for 96 designed SSIBL activities that contribute to students' engagement with the SDGs. Table 1 summarizes the range of SDG-related activities, detailing up to three specific examples within each sub-goal.

All the activities were initiated using contemporary socio-scientific issues, drawing on training ideas, images and artefacts, media sources, video clips and schoolrelated situations observed by the PSTs as they sought out 'teachable events' in their placement schools. The PSTs' reflective accounts highlighted their design intentions alongside what was possible within the context of their school expectations:

As I went around the school, I noticed there were only three bikes in the bike shed, so I started wondering why so few students cycle to school? (Cath, cohort 1)

In the previous lesson, students learnt about respiration and the components required to 'release' energy. They were aware of some of the diseases of the lungs (e.g. emphysema) that can cause reduced breathing and effect respiration. This [SSIBL] lesson was planned to really make them think about [e.g. the impacts of smoking] seemingly different but linked concepts. (Eren, cohort 4)

\section{Raising authentic questions - Ask}

PSTs typically used 'trigger' questions for SSIBL activities, as they found it challenging to support students in asking inquiry questions. However, there were positive instances of PSTs scaffolding students to then ask their own investigable questions (domain of practice; Clarke and Hollingsworth, 2002):

I asked the students 'should we have a fat tax on unhealthy foods'? Then they had to think about what we could find out by going and analysing the menu in the school canteen. (Hayley, cohort 1)

I showed the students the pictures [of different sources of air pollution] and asked them to think about which questions that raised for them. (Jack, cohort 2)

I designed a socio-scientific investigation with the support of my subject mentor, who highlighted that she constantly sees students outside the school gates drinking fizzy drinks and eating junk food. (Andrea, cohort 3)

I began the project by introducing three key socio-scientific issues the world is currently facing using stimulus pictures. These included: plastic in the oceans, recycling materials and sugar addiction. (Roisin, cohort 4)

PSTs were able to locate contemporary local and global issues, such as the causes and effects of climate change, and opportunities related to particular SDGs, and to situate them within science national curriculum topics that they were being asked to plan 
and teach. Starting from curriculum statements proved to be an essential component of successful SSIBL enactment. Many of the SSIBL activities were related to diet and food intake, in support of healthy eating. This focus was as a result mainly of the topics the PSTs were required to teach, but it also fitted well into SDG 3, 'Good health and well-being'.

\section{An inquiry-based approach - Find out}

Analysis of PSTs' lesson designs and resources showed that they commonly encourage students to use online approaches to research, often as part of a homework assignment, or hard-copy information or video analysis in the classroom:

I then showed them short video clips showing each issue in more detail - a Blue Planet clip [Blue Planet II, the BBC documentary broadcast in 2017], a governmental sugar advert and a recycling awareness advert. (Roisin, cohort 4)

To scaffold (domain of practice) this research, the PSTs provided relevant websites and media articles:

After looking into the harmful effects of pollution, students will then research the things being done in London to reduce the pollution, such as 'Boris bikes' [hire bicycles available on London streets] and 'greener buses'. (Ella, cohort 1)

Some, in addition, took the step of supporting students in designing survey questionnaires or interviews to find out opinions and practices from their peers and family members:

On your chart, record information from various people (friends, family, teachers) regarding:

- Do they pay attention to food labels, focusing on the sugar percentage on the foods they buy?

- Has the increase in obesity and type 2 diabetes affected the amount of sugary foods they consume in a day or week?

- Will the sugar tax (explain this to them if needed) affect what foods they buy? (Aysha, cohort 4)

A small number also added scientific data into the mix of evidence being generated, working on scientific inquiry skills specifically:

The next lesson involved going outside and gathering [pollution] samples. Students took samples from different trees and stuck the Sellotape on to a piece of plain white paper, labelling on the paper where the sample has come from. Once back inside the classroom, students used microscopes ... to look at the samples and identify soot from pieces of bark. (Ellie, cohort, 1)

We calculated how many plastic toothbrushes the whole of Year 8 [180 12-13-year-old girls in the school] would have used in their lifetimes. The number was astounding. (Parveen, cohort 4)

I collected some rainwater that had fallen the day before and asked students to test the $\mathrm{pH}$. They were surprised to find that rainwater is naturally slightly acidic. I also made up mock rainwater from countries 
where acid rain is a big concern (China and Russia). Students were able to compare the UK's rainwater with China and Russia. (Karabo, cohort 4)

A number of challenges emerged in terms of PSTs supporting students' creation of survey questions, as well as meaningful analysis and comprehension of the data and evidence they were collecting. Sometimes students arrived at 'findings' without worrying about whether they could substantiate them:

It became apparent when [11-12-year-old] students came to writing up their research that while some groups had done surveys and research, many students had not grasped the scientific concepts and [just] presented 'facts' about the drink they were researching. (Andrea, cohort, 3)

Once again, this provided PSTs with important opportunities to reflect on their own continuing development in terms of how to support and scaffold successful learner outcomes (domain of practice to domain of consequence to personal domain).

\section{Finding a solution - Act}

The SSIBL activities involved some active research, which promoted raising awareness (RA; see Table 1) of issues for students within one or more of the SDGs. Once the 'finding out' phase was complete, PSTs tended to steer students towards one of two main strategies in terms of extending the outcomes into more tangible actions. A popular strategy was to have inquiry culminating in peer presentations of findings, often making recommendations for change at personal and societal levels:

Students presented their solutions to the inquiry - What is the best type of renewable energy resource to use in the following places (Egypt, Switzerland and Australia) and give your reasons? (Ginny, cohort 3)

Occasionally, this was extended to presenting to younger peers, head teachers or external figures the students may have wanted to influence. We classify this as intention to act (IA), by sharing knowledge with others:

The main activity was to write a letter to Donald Trump outlining students' own views about renewable energy, and why the world leaders must continue to fund efforts to make renewable energy our main source of energy and use less coal and other fossil fuels. (Marwa, cohort 4)

The second most commonly used strategy was to stage argumentation, or class debates, where students attempted to use evidence and reasoning for and against a problem, to reach some kind of consensus on potential actions and solutions (Simon and Amos, 2011):

I decided to expose students to a debate on the pros and cons of different renewable energy resources ... Discussion was organised by giving students set time to develop their argument/dialogue, and during the actual debate each group was given a turn to present their argument/ idea, and opportunity was provided for students to respond to each other's ideas. (Uma, cohort 4)

Taking action (TA) at a personal level beyond the classroom proved the most logistically challenging goal for PSTs to support for their students. Where it was achieved, students managed to commit to changing their behaviour(s), and sometimes those 
of their immediate families, for example, by taking a personal pledge to change their eating habits.

As the PARRISE project continued, the SDGs concerning our use and misuse of resources came gradually into focus in the UK, as a result of media exposure. Several of the PSTs chose to situate their SSIBL activity designs in topics related to SDGs 7, 12,13 and 14 (see Table 1). The following cases illustrate some of the designed SSIBL activities, together with certain sensitivities that may exist when teachers plan SSIBL.

\section{PST case studies contributing to SDGs 7, 12, 13 and 14}

\section{Emily (cohort 1)}

As 'green' issues were popular in her school, Emily decided to have her students explore the question:

How can the students help reduce the environmental impact of the school?

The students looked around the school, and in groups they identified a problem and suggested ways to address it. Emily informed them that they would show their results to science teachers and persuade them to use their suggested solutions to make a difference in the school. The lesson involved a class discussion about where they thought the school was going wrong (environmentally speaking). This was run similarly to their student voice session to draw on a familiar framework. Each group discussed their ideas, then nominated a speaker who came and presented ideas to the whole group. When the class had amassed enough ideas, they split into project groups and chose a topic. The final choices were food waste in the dining hall, paper waste in lessons, leaving lights on overnight, unnecessary heating and recycling. Then, for example, the recycling group went around and checked every classroom and wrote down whether there was a recycling bin and whether or not it was being used correctly. Their results were presented on posters, which were peer assessed and displayed in the science classroom.

Emily was able to draw on socio-scientific problems that were important to the students (Ask), and to give them responsibility for carrying out meaningful research in their school (Find out) upon which to make recommendations for solutions (Act). She reflected that: 'While their investigations were more observational than scientifically rigorous, I think they enjoyed the lessons as a change of pace from the usual topic.'

\section{Jyran (cohort 1)}

Jyran was teaching a Year 11 (15-16 year olds) science group about plastics, so he decided to poll them about their views regarding the sale of plastic bottled drinks in the school canteen. He found that the students were naturally engaged in the issue as it connected the curriculum content to real-world experiences. However, extending that interest beyond this into deeper forms of inquiry was a difficult task. In attempting to gain a larger sample of students to poll, he encountered a great deal of resistance once the class time had ended. Some students were wary that by taking a stance on the issue of plastic bottle sales in the canteen, they would antagonize the school management and/or other students.

Jyran's experience of planning SSIBL therefore raises a number of important challenges around whether students feel empowered to put their research and ideas for change out there. His confidence to facilitate this, as a PST working in the school for only a short time, was also an issue. 


\section{Natalie (cohort 4)}

With a Year 9 class (13-14 year olds), Natalie wanted to support learning about home insulation, as she felt that much debate about either using renewable or non-renewable energy resources was missing the point about the dissipation of energy worldwide. Many houses in London were built in the 1800s, and are therefore very 'leaky' in terms of energy flow. She wanted students to inquire into home insulation and how it can be used to make houses more energy efficient. She devised the inquiry question to focus students on the curriculum ideas that she was required to teach. She provided energy fact files and costings (her own research), which the students had to analyse to make decisions about how to heat and insulate a home. The main focus for the students was to design, draw and label their chosen solutions for a model house.

This kind of activity can work well in engaging students actively in SDGs 7, 12 and 13 through SSIBL. Natalie was working with limited time and resources. An example of this kind was developed by Austrian PARRISE partners, which involved experts and stakeholders coming into school as part of promoting action on climate change (Radmann et al., 2018). This approach can improve the authenticity of such an activity.

Upon reflection, Natalie could see that the inquiry was effective in terms of students discovering different types of effective insulation themselves and how they work. She discovered that her students actually preferred this type of inquiry learning as it gave them a sense of ownership, as well as allowing them to use their creativity. She felt that SSIBL also allowed students to be aware of science in everyday life and the relevance of science to them, something that they can engage in. However, she experienced some challenges. She stated that inquiry learning has its limitations, and the pressure of high-stakes national examinations can make science teachers reluctant to give it time. Another perceived challenge was that SSIBL was not accessible for all students. Some students struggled with individual research and independent thinking. She stated that there is also the risk that students will not find the 'correct' information, leaving them at a disadvantage in exams. These kinds of reservations were commonly felt by the PSTs as they tried to enact SSIBL in their placement schools.

\section{Discussion}

The PSTs in the PARRISE project were exposed to pedagogical approaches that enabled them to work towards supporting school science students in taking an 'it matters' approach to their learning. Inquiry learning, both scientific and socio-scientific, has to be structured and guided appropriately for different learners (Banchi and Bell, 2008), and in doing so, PSTs can learn pedagogical skills for development education (Bourn, 2015). There were a number of challenges, as highlighted by Andrea, when students did not build evidence from their research into active outcomes concerning reducing drinking fizzy beverages and the potential health issues (SDG 2). To that end, Julien and Barker's (2009) research indicating that students' information-retrieving skills show little interrogation of content needs to be made explicit in the acquisition of PSTs' professional knowledge. This kind of input into Clarke and Hollingsworth's (2002) external domain then contributes to improved teacher development.

We brought together the SSIBL framework with the Clarke and Hollingsworth (2002) teacher development domains to provide the PSTs with reflective strategies for building socially responsive science lessons. PSTs face various challenges during their initial teacher education programmes, while taking on board a variety of important teaching skills. The SSIBL designs they managed to achieve highlight the early development of such skills, and upon reflection enabled them to identify key 
areas for professional development as they moved into the teaching profession. Even experienced science teachers typically struggle to manage the demands of designing learning through SSIs (Friedrichsen and Sadler, in press).

In addition, scaffolding surveys is crucial to effective gathering of relevant data during SSIBL. Several of the PSTs supported the students in writing survey questions, but unless they have experience of building up expertise in writing short surveys and gathering data, perhaps through interdisciplinary programmes such as 'collapsed days' (Harris and Ratcliffe, 2005), students will not readily recognize what makes a valid survey question. This kind of social science research is valuable in the context of school science lessons, as it supports thinking beyond science as fixed knowledge, and recognizes that both the positive and the negative impacts of scientific and technological endeavours are felt environmentally, economically and societally (Ashley, 2000). The contribution that school science can make to engagement with the SDGs follows on.

\section{Implications}

Training pre-service and experienced science teachers in the knowledge and skills required to adopt a SSIBL approach to teaching science in primary and secondary schools across Europe in the PARRISE project has shown potential for engaging school students in the 2030 Sustainable Development Goals. If we are to enable younger generations to become informed, participatory citizens, willing and able to make wise choices about their lifestyles in the twenty-first century such that at local and global levels we support the health of our planet and people, frameworks such as SSIBL can play a valuable part.

The complexities of issues associated with the SDGs mean a range of pedagogical skills are needed by science teachers to support students in carrying out meaningful SSIBL, while maintaining the focus on science subject knowledge that ultimately supports informed decision-making (Lester et al., 2006). The ability to raise and refine investigable inquiry questions, which are personally meaningful, to interrogate sources of information while understanding the perspectives of different stakeholders (often made almost impossible by the media these days), to reflect on the quality and trustworthiness of data and evidence, and to develop scientific literacy and socio-scientific reasoning skills are all very challenging. PSTs are therefore encouraged to review problems developed in previous SSIBL activities through reflection and enactment. We consider the SSIBL pedagogical approach to be important in terms of teachers linking the ideas of science in curricula with ideas about science (Harlen, 2010) to promote citizenship. In some of the European partner countries, this is wellestablished, but in others, for example in England, convincing initial teacher education providers of the value of such approaches in PSTs' training is challenging. There are naturally other priorities, and training time is limited.

Moreover, the 2030 SDGs and SSIBL activities do not lend themselves best to a single disciplinary approach. What knowledge is needed depends on the question asked. Why people young and old adopt diets that are out of balance and rely on foods from distant parts of the world, rather than on local produce, is a complex problem relying on psychological constructs, an understanding of the politics and economics behind advertising and distribution of food products, and other social attitudes. In developed countries, it is often all too easy to assume a continual supply of 'exotic' foods from across the world, without facing up to the impacts and issues associated 
with that supply. Hence SSIBL needs to be containable by asking focused and feasible driving questions (Levinson et al., 2012).

Adopting SSIBL could benefit from co-design frameworks (Kyza and Nicolaidou, 2017), where cross-disciplinary teams of teachers with commonly identified purposes design resources and strategies for SSIBL-like approaches. Levinson's work $(2009,2014)$ on the social and political dynamics of aluminium production and recycling demonstrates the potential for enhanced subject knowledge through a SSIBL approach. We are also in the process of developing a project that builds on PARRISE with colleagues in East Africa, for example. Through bringing science PSTs together from England and from countries in Africa, as they train in very different local circumstances, we hope to support authentic understanding of issues that connect us as global citizens. This then allows for cross-cultural understanding in engaging with the SDGs in schools, while drawing on crucial subject knowledge (Lester et al., 2006).

Getting the 'wrong answer' is always a risk in open-ended inquiries, but only if the main focus of the answer is conceptual knowledge. In these cases, scientific knowledge is an input to promote deeper critical thinking, rather than an output. Our research with PSTs further shows that this practice has influenced more established teachers (Amos et al., in press). Through collaborative learning, progressive scaffolding enables students both to use and to build scientific knowledge through inquiry, and teachers might be more able to see SSIBL and other inquiry methods as ways to secure more substantive learning and to link with lived experiences (Sadler et al., 2007) in the context of the aims of the SDGs.

\section{Notes on the contributors}

Ruth Amos is Lecturer in science education at UCL Institute of Education, London, where she works on pre-service teacher education programmes. Prior to teaching in London schools, Ruth was an environmental chemist. She has co-authored articles on socio-scientific issues, working on the EU PARRISE project, and has contributed to teacher development programmes in China, India and the UAE. Her current research interests include impacts of education for environmental stewardship in primary and secondary schools.

Ralph Levinson is Reader in Education at UCL Institute of Education, London. He has authored books and articles on socio-scientific issues, political aspects of science education, chemistry education and arts in science education. He has been a keynote speaker at many national and international meetings and played a prominent role in EU projects. His present research interests focus on the role of neo-liberalism in science education policy and school student engagement in scientific research.

\section{References}

Abd-El-Khalick, F., Boujaoude, S., Duschl, R., Lederman, N.G., Mamlok-Naaman, R., Hofstein, A., Niaz, M., Treagust, D. and Tuan, H.-L. (2004) 'Inquiry in science education: International perspectives'. Science Education, 88 (3), 397-419.

Amos, R., Knippels, M.-C., Kyza, E. and Levinson, R. (2018) 'Theme editorial: Science and society'. School Science Review, 371, 29.

Amos, R., Knippels, M.-C. and Levinson, R. (in press) 'Socio-scientific inquiry based learning: Possibilities and challenges for teacher education'. In Evagorou, M., Dillon, J. and Nielsen, J. (eds) A Pedagogy for Relevance through Socio-Scientific Issues (tbc). New York: Springer.

Ashley, M. (2000) 'Science: An unreliable friend to environmental education?'. Environmental Education Research, 6 (3), 269-80.

Banchi, H. and Bell, R. (2008) 'The many levels of inquiry'. Science and Children, 46 (2), 26-9. 
Bourn, D. (2015) 'A pedagogy of development education: Lessons for a more critical global education'. In Maguth, B.M. and Hilburn, J. (eds) The State of Global Education: Learning with the world and its people. New York: Routledge, 13-26.

Bourn, D. (2016) 'Teachers as agents of social change'. International Journal of Development Education and Global Learning, 7 (3), 63-77.

Bourn, D., Hunt, F. and Bamber, P. (2017) A Review of Education for Sustainable Development and Global Citizenship Education in Teacher Education (Global Education Monitoring Report Background Paper). Paris: United Nations Educational, Scientific and Cultural Organization.

Brickhouse, N. (2011) 'Scientific literacy for bringing in the outsiders'. In Linder, C., Östman, L., Roberts, D.A., Wickman, P.-O., Erickson, G. and MacKinnon, A. (eds) Exploring the Landscape of Scientific Literacy. New York: Routledge, 193-204.

Brickman, P., Gormally, C., Armstrong, N. and Hallar, B. (2009) 'Effects of inquiry-based learning on students' science literacy skills and confidence'. International Journal for the Scholarship of Teaching and Learning, 3 (2), Article 16, 1-22. Online. https://tinyurl.com/y5nqs6wp (accessed 12 March 2019).

Burton, A. (2012) 'Titanium dioxide photocleans polluted air'. Environmental Health Perspectives, 120 (6), A229. Online. https://tinyurl.com/y62f2vdc (accessed 11 March 2019).

Buxton, C.A. (2006) 'Creating contextually authentic science in a "low-performing" urban elementary school'. Journal of Research in Science Teaching, 43 (7), 695-721.

Clarke, D. and Hollingsworth, H. (2002) 'Elaborating a model of teacher professional growth'. Teaching and Teacher Education, 18 (8), 947-67.

Davis, E.A. and Miyake, N. (2004) 'Explorations of scaffolding in complex classroom systems'. Journal of the Learning Sciences, 13 (3), 265-72.

DfE (Department for Education) (2015) 'Statutory guidance: National curriculum in England: Science programmes of study'. Online. http://tinyurl.com/qjdxyph (accessed 12 March 2019).

Etherington, R. (2011) 'Catalytic Clothing by Helen Storey and Tony Ryan'. Dezeen, 15 June. Online. www.dezeen.com/2011/06/15/catalytic-clothing-by-helen-storey-and-tony-ryan/ (accessed 25 March 2019).

Friedrichsen, P. and Sadler, T. (in press) 'Supporting teachers in the design and enactment of socioscientific issues based teaching in the US'. In Evagorou, M., Dillon, J. and Nielsen, J. (eds) A Pedagogy for Relevance through Socio-Scientific Issues (tbc). New York: Springer.

Funtowicz, S.O. and Ravetz, J.R. (1993) 'Science for the post-normal age'. Futures, 25 (7), 739-55.

Funtowicz, S.O. and Ravetz, J.R. (1994) 'The worth of a songbird: Ecological economics as a post-normal science'. Ecological Economics, 10 (3), 197-207.

Gray, D., Colucci-Gray, L. and Camino E. (2009) Science, Society and Sustainability: Education and empowerment for an uncertain world. New York: Routledge.

Harlen, W. (ed.) (2010) Principles and Big Ideas of Science Education. Hatfield: Association for Science Education.

Harris, R. and Ratcliffe, M. (2005) 'Socio-scientific issues and the quality of exploratory talk - what can be learned from schools involved in a "collapsed day" project?'. Curriculum Journal, $16(4), 439-53$.

Iannucci, E. (2017) 'Sierra Rutile bribery scandal unlikely to affect lluka operations'. Mining Weekly, 16 August. Online. www.miningweekly.com/article/sierra-rutile-bribery-scandal-unlikely-to-affectiluka-operations-2017-08-16 (accessed 25 March 2019).

Julien, H. and Barker, S. (2009) 'How high-school students find and evaluate scientific information: A basis for information literacy skills development'. Library and Information Science Research, $31(1), 12-17$.

Krstovic, M. (2014) 'Preparing students for self-directed research-informed actions on socioscientific issues'. In Bencze, L. and Alsop, S. (eds) Activist Science and Technology Education. Dordrecht: Springer, 399-417.

Kyza, E.A. and Nicolaidou, I. (2017) 'Co-designing reform-based online inquiry learning environments as a situated approach to teachers' professional development'. CoDesign, 13 (4), 261-86.

Lalji, N. (2007) 'The resource curse revised: Conflict and coltan in the Congo'. Harvard International Review, 29 (3), 34-7.

Lester, B.T., Ma, L., Lee, O. and Lambert, J. (2006) 'Social activism in elementary science education: A science, technology, and society approach to teach global warming'. International Journal of Science Education, 28 (4), 315-39.

Levinson, R. (2009) 'The manufacture of aluminium and the rubbish-pickers of Rio: Building interlocking narratives'. School Science Review, 90 (333), 119-24. 
Levinson, R. (2010) 'Science education and democratic participation: An uneasy congruence?'. Studies in Science Education, 46 (1), 69-119.

Levinson, R. (2014) 'Undermining neo-liberal orthodoxies in school science: Telling the story of aluminium'. In Bencze, L. and Alsop, S. (eds) Activist Science and Technology Education. Dordrecht: Springer, 381-97.

Levinson, R., Hand, M. and Amos, R. (2012) 'What constitutes high-quality discussion in science? Research from the Perspectives on Science course'. School Science Review, 93 (344), 114-20.

Levinson, R., Knippels, M.C., Van Dam, F., Kyza, E., Christodoulou, A., Chang-Rundgren, S.N., Grace, M., Yarden, A., Abril, A., Amos, R., Ariza, M.R., Bächtold, M., Van Baren-Nawrocka, J., Cohen, R., Dekker, S., Dias, C., Egyed, L., Fonseca, M., Georgiou, Y., Hadjichambis, A., Van Harskamp, M., Hasslöf, H., Heidinger, C. Hervé, N., Karpati, A., Keedus, K., Kiraly, A., Lundström, M., Molinatti, G., Nédélec, L., Ottander, C., Ottander, K., Quesada, A., Radits, F., Radmann, D., Rauch, F., Rundgren, C., Simonneaux, L., Simonneaux, J., Sjöström, J., Verhoeff, R., Veugelers, W. and Zafrani, E. (2017) Science and Society in Education: Socio-scientific inquiry-based learning: Connecting formal and informal education with society. Utrecht: PARRISE.

NACE (National Advocacy Coalition on Extractives) (2009) Sierra Leone at the Crossroads: Seizing the chance to benefit from mining. Freetown: National Advocacy Coalition on Extractives.

Owen, R., Macnaghten, P. and Stilgoe, J. (2012) 'Responsible research and innovation: From science in society to science for society, with society'. Science and Public Policy, 39 (6), 751-60.

Radmann, D., Rauch, F. and Schmölzer, B. (2018) 'Collaborative science teacher education through inquiry on climate issues'. School Science Review, 100 (371), 36-9.

Ravetz, J. and Funtowicz, S. (1999) 'Editorial: Post-normal science - an insight now maturing'. Futures, 31 (7), 641-6.

Rocard, M., Csermely, P., Jorde, D., Lenzen, D., Walberg-Henriksson, H. and Hemmo, V. (2007) Science Education Now: A renewed pedagogy for the future of Europe. Brussels: European Commission.

Roth, W.-M. (1997) 'From everyday science to science education: How science and technology studies inspired curriculum design and classroom research'. Science and Education, 6 (4), 373-96.

Sadler, T. (2009) 'Situated learning in science education: Socio-scientific issues as contexts for practice'. Studies in Science Education, 45 (1), 1-42.

Sadler, T.D., Barab, S.A. and Scott, B. (2007) 'What do students gain by engaging in socioscientific inquiry?'. Research in Science Education, 37 (4), 371-91.

Simon, S. and Amos, R. (2011) 'Decision making and use of evidence in a socio-scientific problem on air quality'. In Sadler, T.D. (ed.) Socio-Scientific Issues in the Classroom: Teaching, learning and research. Dordrecht: Springer, 167-92.

SSL (Statistics Sierra Leone) and ICF Macro (2009) Sierra Leone Demographic and Health Survey 2008. Calverton, MD: Statistics Sierra Leone and ICF Macro. Online. https://dhsprogram.com/ pubs/pdf/FR225/FR225.pdf (accessed 30 October 2018).

Sutcliffe, H. (2011) A Report on Responsible Research and Innovation. Brussels: European Commission.

UN (United Nations) (2015) 'Transforming our world: The 2030 agenda for sustainable development'. Online. http://tinyurl.com/q9k2rk9 (accessed 12 March 2019).

UNDP (United Nations Development Programme) (2018) Human Development Indices and Indicators: 2018 statistical update. Online. http://hdr.undp.org/sites/default/files/2018_human_ development_statistical_update.pdf (accessed 15 April 2019).

Von Schomberg, R. (2014) 'The quest for the "right" impacts of science and technology: A framework for responsible research and innovation'. In Van den Hoven, J., Doorn, N., Swierstra, T., Koops, B.-J. and Romijn, H. (eds) Responsible Innovation 1: Innovative solutions for global issues. Dordrecht: Springer, 33-50.

Yates, J. (2018) How Can the Philosopher's Backpack Enrich Critical Global Thinking? (Global Learning Programme Innovation Fund Research Paper 6). London: Global Learning Programme.

Zangori, L., Peel, A., Kinslow, A., Friedrichsen, P. and Sadler, T.D. (2017) 'Student development of model-based reasoning about carbon cycling and climate change in a socio-scientific issues unit'. Journal of Research in Science Teaching, 54 (10), 1249-73. 